\title{
TEACHING AND LEARNING SCIENCE AND MATHEMATICS THROUGH TECHNOLOGY PRACTICE
}

\section{INTRODUCTION}

In this chapter we review studies of the engagement of students in design projects that emphasise integration of technology practice and the enabling sciences, which include physics and mathematics. We give special attention to affective and conceptual outcomes from innovative interventions of design projects.

This is important work because of growing international concern that demand for professionals with technological expertise is increasing rapidly, while the supply of students willing to undertake the rigors of study in the enabling sciences is proportionally reducing (e.g., Barringtion, 2006; Hannover \& Kessels, 2004; Yurtseven, 2002). The net effect is that the shortage in qualified workers is having a detrimental effect upon economic and social potential in Westernised countries (e.g., Department of Education, Science and Training [DEST], 2003; National Numeracy Review Panel and National Numeracy Review Secretarial, 2007; Yurtseven, 2002). Interestingly, this trend is reversed in developing economies including China and India (Anderson \& Gilbride, 2003).

The ever-increasing technological demands of the $21^{\text {st }}$ Century require all citizens to become mathematically, scientifically, and technologically literate. Those without these capacities will become disadvantaged economically and socially within society (Australian Academy of Technological Science and Engineering [ASTE], 2008). The changing technological demands of society and the falling proportion of participating students in the enabling sciences have implications for pedagogy and curriculum design.

Past learning models where mathematics and science concepts are learned quite separately from each other have been under challenge for some time. Criticisms of this curriculum models come from the reported limited transfer of mathematics and science concepts to applications in real-world contexts (Wilhelm, Sherrod, \& Walters, 2008). Traditional mathematics teaching is particularly criticised for fostering a view that mathematics is a decontextualised domain of study. The teaching of the enabling sciences through design processes associated with technology practice is worth examining as a potential solution to increasing student participation in the study of the enabling sciences, in part because it potentially

A.T. Jones \& M.J. de Vries (eds.), International Handbook of Research and Development in Technology Education, 00-00.

(C) 2009 Sense Publishers. All rights reserved. 
NORTON \& RITCHIE

offers a common context with which to study technology, mathematics, and science.

\section{THE CHANGING NATURE OF TECHNOLOGY EDUCATION}

In 1987 the Australian Educational Council (AEC) began a series of initiatives that led to the 1994 nationally agreed curriculum statements that established technology as one of eight key learning areas. Similar approaches have been adopted in the USA with their Standards of technological literacy: Content for the study of technology (International Technology Education Association [ITEA], 2007, 2008) and other nations, all responding to the recognition of the increasingly important role of technology in society.

Technology is broadly defined as the application of knowledge and resources that are used to extend human capabilities (Australian Education Council [AEC], 1994; ITEA, 2007). Lewis (2006) cites a number of authors to define the processes of technology in which 'generating a design', 'making a plan', and 'evaluating a design' are the central processes of technology learning and practice. Technological problem solving essentially combines principles of design with the material aspects of production to satisfy a material need. Other authors note that the design process is part of procedural knowledge, or 'knowing how to do it', that is highly dependent upon contextual knowledge (e.g., McCormick, 1997).

The major change in emphasis in technology education has been a shift from skill development to an emphasis on generic problem solving and ways of thinking (Custer, 2003). Today a technically literate person is someone who understands technology, how it shapes society, and how to 'do' technology that includes designing things to solve practical problems (e.g., ITEA, 2008; National Academy of Engineering, 2008a).

Technology curriculum documents attempt to provide thinking frameworks that encourage students to be creative and innovative. For example, the 'technology practice' model of Queensland Studies Authority (QSA, 2003) in Australia lists key processes of investigation (examining, analysing, researching...); ideation (generating, planning, designing...); production (creating, developing, managing, making...), and evaluating (testing, judging, reflecting, and comparing...). Such rubrics imply that problem solving, including solving problems associated with design, can be taught as a generic set of skills within the domain of technology, and that these could even be transferred to such other domains as mathematics and science. Yet, McCormick (1997) argued that such assumptions have little empirical support.

\section{CURRICULUM CONSIDERATIONS FOR LEARNING SCIENCE AND MATHEMATICS THROUGH TECHNOLOGY PRACTICE}

The idea of teaching science and mathematics through the practice of design became a topic of discussion from the 1960s. Lewis, Barlex, and Chapman (2007) reported that in the UK efforts were made to establish science and technology as a 
single examinable subject. Similar science and technology integration curriculum models were described in other Western nations including Canada (e.g., Lewis, Barlex, \& Chapman, 2007), The Netherlands (e.g., de Beurs, 2000), and the USA (e.g., National Academy of Engineering, 2008b) throughout the 1980s and 1990s.

Design projects offer a rich context in which students can transform their science and mathematics understandings. Learning science and mathematics through design projects can be viewed as 'situated learning' (Wicklein \& Schell, 1995). From a situated learning perspective, students working collaboratively on design projects might demonstrate increased use of knowledge in different situations (potentially across subject domains), and improved problem solving and social outcomes. The degree to which technology practice might offer increased understanding, develop general problem solving skills, and engage students in the learning of the enabling sciences is examined below.

Several authors have noted that classroom design projects can give a task 'authentic purpose' that leads to high student engagement (e.g., American Association for the Advancement of Science [AAAS], 1993; Dow, 2006; ITEA, 2007; Lewis, 2006; McNair \& Clarke, 2007; Mettas \& Constantinou, 2007; Norton, McRobbie, \& Ginns, 2007). Authenticity has two aspects: personal authenticity and cultural authenticity (McCormick, 2004). Personal authenticity means an activity has meaning and value for the learner. In contrast, a task with cultural authenticity has value beyond the individual and even the classroom; that is, the task is worthy of completion and/or the solution to a problem is likely to benefit the wider community.

Roth (1998) reported that technology-design projects (also called engineeringbased projects) offer students the opportunity to develop rich technology and science language by engaging in activity that was personally relevant. Lewis, Barlex and Chapman (2007) cited the Engineering Council's (1990) definition of an engineer as "one who acquires and uses scientific, technical and other pertinent knowledge and skills to create ...” (p. 10). Roth found that engaging children in engineering and design projects changed the nature of classroom learning from children attempting to mimic the teacher's definitions and language to children using the language of science in activities they perceived as personally authentic.

The critical importance of students developing language from their personal engagement with the phenomena of science is a recurrent theme in the literature on authentic learning in science (e.g., Roth, 2005). Earlier, Lemke (1990) commented that learning in science means learning to 'talk science'. Implicit in 'talking' science is the engagement of students in the practices of science. While language is central to thinking, it is accompanied by other attributes - including purpose, procedures, and conceptual knowledge - that may overlap to varying degrees. The extent of overlap determines the extent to which students can engage with the practices of science and technology simultaneously (McCormick, 2004). Yet, Roth (1998) argued that the study of technology and science are mutually supportive practices since engaging in technology-based activities overlaps with the practices of science. 
Even though Lewis (2006) found considerable convergence between science and technology reasoning, mental models, testing processes, and dependence upon overlapping content knowledge, he also reported differences in purpose, the role of constraints, the role of failure, and the greater importance of context in technology. Overall, he asserted that science and technology were potentially mutually supportive discourses, concluding: "The act of designing introduces problems and challenges in classrooms that can be resolved by knowledge of science” (p. 276). In contrast, McCormick (2004) noted that in traditional approaches to science, teachers have tended to focus on abstraction or the stripping away of context, a practice not shared by most technology educators. Yet, science educators who advocate context-based approaches to science do not support a decontextualised treatment of science concepts either (see King \& Ritchie, in press).

Another distinction between science and technology teaching McCormick (2004) makes is that cognitive processes differ according to the domain of thinking, and frequently those domains are distinctly different in technology and science. Similarly, Barlex and Pitt (2000) noted that the thinking demands of science and technology are quite distinct. For example, they considered that the essence of science is the production and testing of knowledge while technology practice is primarily concerned with "transforming this and other sorts of knowledge into techniques and artefacts for which there is a human demand" (p. 5). Benson (2001) supported this argument with his contention that since science and technology are so different it is illogical to subsume them under one "science and technology label” (p. 6).

A further concern was made by Paechter (1995) who noted that, in secondary schools, teachers have such divergent 'subject cultures' that agreement on common learning goals would be difficult to reach. The divergent subject cultures develop from different values placed upon abstraction and context, with technology tending to focus on relevance to an application, and science (and mathematics) upon theories and abstractions. As noted above, these differences in subject culture are manifested in the language and processes involved in teaching as well as assessment models used to grade and reward students (McCormick, 2004). In technology, students are generally assessed according to how the product performs, while in science students are more likely to be assessed on the quality of their explanations of underlying principles.

As with science, learning mathematics through design activities has the potential to give purpose to and generate positive attitudes towards mathematics and perceptions about the nature and value of mathematical endeavour (Norton, 2006a, 2006b; Norton \& Cooper, 2008; Wicklein \& Schell, 1995). However, relatively little research has been conducted to determine the extent to which mathematical concepts can be effectively developed through integrated mathematics and technology activities. McCormick and Evans (1998) argued that different classroom practices in mathematics and technology classes could hinder the simultaneous learning of technology and mathematics in integrated tasks. They found, for example, that in technology classrooms the teacher did the mathematical work to ensure production progress. Furthermore, they asserted that students' 
fragile and varied understanding of mathematics was frequently not sufficient to make sense of the mathematics concepts when they were applied in authentic contexts.

A different outcome was reported following an evaluation of a large-scale intervention of an integrated program in primary schools - known as the New Basics - enacted by Education Queensland (2003) in Australia. This curricular innovation emphasises student engagement in integrated projects known as 'rich tasks'. These tasks provided opportunities for students to learn mathematical concepts in the context of real-world problems (e.g., travel itineraries, Pi in the sky, and international trade). The State's report on the project (Education Queensland, 2004) indicated that students whose schools adopted this approach were not disadvantaged on standardised tests. One plausible reason for this anomalous result is that, in most cases, the schools also sustained a supplementary program of mathematics independent of the rich tasks.

An independent report on the New Basics by Cooper, Nuyen, and Baturo (2003) found that rich tasks were inadequate on their own to teach, assess, and report on the learning of mathematics, and that there were major components of mathematics that needed to be taught outside of the tasks. This suggests that without the parallel curriculum of mathematics, student learning may have been minimal for many students, as was the case for learning science in the robotics study reported by Norton et al. (2007).

\section{TEACHING AND LEARNING SCIENCE AND MATHEMATICS THROUGH TECHNOLOGY PRACTICE}

From the perspective of the classroom teacher, a critical question is which comes first in the process of integrated science and technology learning? Is it better to teach the science and then apply it in a technological context, or to learn the science through engagement with technology practice? One consideration is that the application of science in subsequent technology contexts runs the risk of technology being seen as 'applied science', a description not favoured by some authors not least because science is cast in a 'a gatekeeper' role that potentially limits entry to technology (e.g., Gardner, Penna, \& Brass, 1990).

Several design projects involving children from Year 2 to Year 7 across the US, Canada, and Australia reported students' appropriation of canonically accurate science language as the artefacts took shape (Roth, Tobin, \& Ritchie, 2001). This was particularly pronounced when the teacher purposefully introduced the language of science 'just in time' for the students to learn the related scientific concept in-the-making of the artefact (Ritchie, 1999; Ritchie \& Hampson, 1996). These studies assumed the situated and contingent nature of design activities. As Roth et al. argued:

Designing is not a cognitive activity that can be reduced to individual mental processes. Decisions taken by principal actors, or owners of projects, cannot be understood apart from the tools, materials, artefacts, teacher interdictions 
NORTON \& RITCHIE

and constraints, and the emergent properties of collective, discursive and material activity, and design artefacts. (p. 29)

Furthermore, they recognised that emerging artefacts provide a context for subsequent design moves that lead to additional opportunities for learning science concepts.

Norton et al. (2007) reported on students' engagement in integrated science and technology projects making logo-controlled robots in two classes. They found that most of the science remained implicit. More specifically, the few students who had completed a prior physics unit took account of concepts such as friction and leverage, and used the language of these phenomena, yet the designs of the majority of students paid scant regard to the physics of mechanics. This was hardly surprising since almost all aspects of the classroom environment did not support the abstraction of science. The assessment focused on a working product, most teacher support was related to helping students to get their product to work, and most student time was spent designing and particularly building working robots. Analysis of classroom discourse indicated that compared to a 'science only' focused classroom, the teacher's use of science language was negligible and student-to-student discourse was essentially bare of science language and concepts for most groups. A manifestation of the different views that teachers had of the purpose of technology and science was seen in their planning of the unit: They did not have a clear goal to make explicit the learning of science concepts. In addition, in one of the classes there was not a suitable forum for discussing the underpinning science, and in the classes most students simply did not have access to the linguistic resources with which to engage in discussions about the science underpinning the design project. McCormick (2004) and McCormick, Davidson, and Levinson (1995) reported similar outcomes from other technology projects.

In another technology-based learning study in Years 3 to 7, students were asked to design a theme park ride (Norton, 2006a). The first step was to experience the forces first-hand by going to a theme park where an onsite engineer guided the students by explaining much of the physics underpinning the rides. Some Year 4 and 5 boys subsequently chose to build a model of the Centrifugal Ride. The concept of centripetal force made sense to them after their visit: It was the centreseeking force that kept them moving in a circle when they were pinned to the wall of the ride despite the floor falling beneath them. The release of centripetal force also spun the water out of a lettuce colander, and they adapted this to make their model of the ride. In this instance, the science was experienced and a language linked to that experience such that the students could think about and communicate about the science phenomena when designing and making their ride. Analysis of the discourse describing their projects indicated that these young students fluently used the language of science, including terms such as force, push, magnets, magnetism, speed, going faster, slowing down (acceleration), electricity, minutes, seconds, watts, kilowatts, power, and so on. In this study, the focus on classroom activity was upon making science explicit, applying the laws of physics, and using measurement and geometry aspects of mathematics to design and build the rides. 
In a more recent study reported by Norton and Cooper (2008), two case studies had an explicit focus on science, one on insect ecology and the other on the sun, including seasons and telling the time by the sun. In regard to the insect ecology study the design brief was to construct a 'bug catcher'. Opportunities for learning science occurred as a result of collecting insects and making observations about numbers, types, and locations of the insects. The Year 3-4 students asked questions such as "Are there more bugs in some parts of the school?", "Do different ants come out at night?”, "Do all ants eat honey?”, and "Do more butterflies come out after rain?” In this instance, the design of the bug catcher was an integral part of the inquiry process of learning science, as recommended in the contemporary science education literature where students seek to answer their own questions (e.g., Duschl, 2008). A scientific need provided a rationale for constructing a bug catcher, a reason to engage in the practice of science, and a context to learn the language of science. It could also be seen that the need to solve a science question provided a rationale to learn technology and design principles.

The classroom teacher in both the bug catcher and the sundial projects reported high levels of student motivation and engagement. However, while the learning of science concepts associated with insect ecology and data presentation seemed to be well catered for in the bug collection project, success in meeting technology outcomes was less clear. The design practices of investigate, ideate, produce, and evaluate were not realised, much of the production stage was craft orientated and the evaluation was largely coincidental. The students applied the mathematics of scale drawing to sketching designs, but there was no evidence to suggest that these diagrams guided construction. As in the previous study (i.e., Norton, 2006a), construction tended to be dictated by the practicalities of cutting and fixing materials. It appeared that much of the 'thinking' processes of technology had not been abstracted during the project, possibly due to the teacher's limited familiarity with the technology curriculum (see also de Beurs, 2000), but also because of the different demands and ways of working in the various subject domains.

In the sundial-based integrated technology/mathematics/science project described by Norton and Cooper (2008), somewhat different integration processes were observed. The composite class of Year 4-7 students wanted to make a sundial and sundial mount because the school's old sundial had been eaten away by termites and the students wished to replace it with a robust artefact. This need provided a reason to research various sundial designs as well as to assess various materials. The teacher recognised considerable overlap between the "natural and processed materials" strand in science and the "materials" strand in the technology curriculum. In this project, the students evaluated various sundial designs and built prototypes with cardboard. They then contracted the local metal industry to manufacture the sundial to their specifications.

The observations of student technology-based projects in the contexts of robots, theme park rides, bug catchers, and sundials support Roth's (2005) findings that student engagement in design-based activity had the effect of transforming the classroom discourse from teacher-centred to child-centred learning communities. Learning mathematics through technology practice has potential to create learning 
environments that are rich in mathematics learning and application opportunities (e.g., Norton, 2005; Norton \& Cooper, 2008). Realising this potential in typical classroom settings is a challenge for the same reasons as is the case with science learning. Some of these challenges, faced by teachers implementing engaging technology projects that enhance the likelihood for science and mathematics learning outcomes, are now considered.

\section{CHALLENGES THAT CONFRONT SCIENCE AND MATHEMATICS TEACHERS IMPLEMENTING TECHNOLOGY-BASED DESIGN ACTIVITIES}

An ongoing challenge for science and mathematics educators has been to support student learning in ways that assist students to apply the concepts beyond the settings in which they are learnt. The criticism of traditional textbook-based learning is that many students do not recognise and apply science and mathematics concepts outside of their decontextualised classroom activities. The studies reviewed in this chapter suggest that while students may well have been engaged in the manipulation of materials to produce artefacts in design activities, without skilful teacher intervention (e.g., Ritchie, 1999), many students do not independently develop deep understanding of science (and mathematical) concepts. Not surprisingly, teacher support is also a likely requisite for successful implementation of design projects (Roth et al., 2001).

There are two ways for teachers to scaffold technology practice to enhance mathematical and scientific understanding. The first is a 'just in case' approach. This is typified by introducing the concept in mathematics or science class before it is needed in the design project. For example, proportion was taught using models of coloured counters, different quantities of mixtures, and scale in diagrams and maps before introducing it in the form of ratio in gearing within a design setting (Norton, 2006b). In this model, the design activity becomes an opportunity to apply a mathematical concept in an authentic setting. One advantage of this approach to the integrated learning of technology and mathematics is that the teacher can plan ahead to address specific aspects of the curriculum purposefully, a significant factor considering the necessity imposed by most education authorities that require mathematical concepts, for example, to be taught sequentially (e.g., multiplication before division, and differentiation before integration).

The second approach can be called 'just in time'. In this approach, mathematics or science concepts relevant to the unfolding artefact are taught as the need arises. This gives an immediate purpose for learning the mathematics or science concept. Potentially, this form of integration is powerful and has the theoretical support of those who value situated learning (e.g., Brown, Collins, \& Duguid, 1989; Lave \& Wenger, 1990). While this just in time approach has not been observed regularly in mathematics education studies, it is more commonly reported in the science education literature (see Roth et al., 2001).

Teachers attempting to implement either form of scaffolding face formidable challenges associated with the use of different language, different procedures, having different backgrounds or contextual knowledge, and different classroom 
management processes in technology, science, and mathematics classrooms. In addition, the students become increasingly cognisant of the particular cultures associated with learning in each subject, and contribute to the maintenance of conforming practices (i.e., cultural reproduction). Considering the divergent activity associated with the different enabling sciences, a 'just in time' approach places very high demand upon teachers' domain and pedagogic knowledge.

Given the reports of difficulties finding teachers with adequate breadth and depth of mathematical and science knowledge (e.g., National Numeracy Review Panel \& National Numeracy Review Secretariat, 2007), the expectation that teachers would also have widespread experience with technology practice may be unrealistic. While support for integrated learning has been reported from primary to tertiary levels (e.g., Wilhelm et al., 2008), clearly concerns about depth of knowledge become increasingly significant as children progress from primary school settings to secondary schools, with distinct language, procedural and conceptual knowledge, and staff subcultures in each subject domain.

\section{CONCLUDING REMARKS}

The use of technology practice as a framework for the learning of mathematics and science offers considerable potential for students to develop deep understanding of phenomena in relevant contexts. As such, design projects can have a multiplier effect on learning science and mathematics. There are possibly three mechanisms for effect. The first is additional time. Students can learn mathematics and science in their allocated time in the school timetable and have additional time to apply scientific and mathematical thinking while engaged in a technology-based project. Second, students are afforded additional representations. For example, Norton (2006b) described students learning ratio with varying representations in mathematics and applying those understandings in gearing contexts as part of a technology project. The third multiplier effect is frequency of engagement. Students have the potential of engaging with mathematical and scientific concepts over a number of subject domains in a teaching week.

Some authors suggest that specific knowledge of mathematics and science concepts mutually supports the design, production, and evaluation processes of technology (e.g., Roth, 1995; Wicklein \& Schell, 1995). Technology practice can be seen as a mechanism to integrate the learning of the enabling sciences, and has considerable potential to address many of the problems in engaging students in learning mathematics and science, including those related to a fragmented and disconnected curriculum and teacher-centred approaches. However, realising this potential is not without its challenges, and mounting evidence suggests that these challenges become increasingly important as students pass through the school system and each subject domain develops disparate language conventions, contextual knowledge, and procedures including problem solving procedures.

Primary and secondary teachers face different obstacles in implementing design projects. In primary schools, one teacher generally teaches all key learning areas and has considerable flexibility in planning the curriculum. Primary teachers might 


\section{NORTON \& RITCHIE}

overcome some obstacles by integrating discipline learning in design projects through the 'just in case' model. This model might be enacted more easily because there is a gradual transition towards increased integration, supported by appropriate curriculum material and professional assistance. The relatively low assumptions of student contextual, subject, and procedural knowledge also facilitate a 'just in case' model of scaffolding.

The successful implementation of the 'just in time' model is likely to require greater discipline knowledge and familiarity with technology practice both in terms of procedural and conceptual knowledge (McCormick, 1997). While secondary teachers are more likely to have the requisite specialist background in a particular discipline and access to relevant resources, they are usually less experienced in designing integrated activities. In contrast, primary teachers have indeed used this approach successfully in curricular innovations studied (e.g., Roth et al., 2001). Furthermore, few secondary teachers have the timetable flexibility and breadth of discipline and pedagogic knowledge to attempt integration of this nature. Secondary teachers might, however, aim for more mutually supportive teaching relationships across discipline boundaries with their colleagues. Through coordination, teachers of technology, mathematics, and science might become informed of the teaching goals of the other disciplines and plan their curricula such that the different subjects support each other. For example, a physics unit on forces and vectors might be planned to coincide with teaching rates of change and modelling polynomials in mathematics, and Newtonian physics in science such that students' conceptual development could be reinforced through the design of machines with a purpose.

A deeper collaborative relationship between secondary teachers of technology, mathematics, and science could be developed with adequate resources, including time for in-depth planning. Collaboration would include the co-ordination of curricula to the extent of sharing some common tasks. Research into the effects of different organisational and leadership structures could illuminate how teachers might initiate such curricular initiatives (see Ritchie, Tobin, Roth, \& Carambo, 2007).

\section{REFERENCES}

American Association for the Advancement of Science [AAAS]. (1993). Benchmarks for science literacy: Project 2061. New York: Oxford University Press.

Anderson, L., \& Gilbride, K. (2003). Pre-university outreach: Encouraging students to consider engineering courses. Global Journal of Engineering Education, 7(1), 87-93.

Australian Academy of Technology Science and Engineering [ATSE]. (2008). Technology education essential. Retrieved 8 November 2008 from: http://www.atse.org.au/index.php?sectionid=1226

Australian Education Council [AEC]. (1994). A statement on technology for Australian Schools. Carlton, Vic: Curriculum Cooperation.

Barrington, F. (2006). Participation in year 12 mathematics across Australia 1995-2004. Melbourne, Vic: ICEME/AMSI, University of Melbourne.

Barlex, D., \& Pitt, J. (2000). Interaction, the relationship between science and design technology in the secondary school curriculum. London: Engineering Council. 


\section{SCIENCE AND MATHEMATICS THROUGH TECHNOLOGY PRACTICE}

Benson, G. (2001). The unrealized potential of everyday technology as a context for learning. Journal of Research in Science Teaching. 28(7), 730-745.

Brown, J.S., Collins, A., \& Duguid, S. (1989). Situated cognition and the culture of learning. Educational Researcher, 18(1), 32-42.

Cooper, T., Nuyen, A., \& Baturo, A. (2003). Rich task project: Integrated mathematics outcomes with rich tasks within a productive pedagogies framework. Queensland University of Technology. Retrieved September 1, 2008, from: http://education.qld.gov.au/corporate/newbasics/ pdfs/richtaskrep3-final-8.4.03.pdf

Custer, R. (2003). Technology education in the United States - A status report. In G. Martin \& H. Middleton (Eds.), Initiatives in technology education: Comparative perspectives (pp. 16-29). Brisbane, Qld: Technical Foundation of America/CTER, Griffith University.

de Beurs, C. (2000). Technology for 15+. Integration of technology in science curriculum of upper level secondary education in the Netherlands. In R. Kimbell (Ed.), Design and technology international millennium conference, England. Available from Loughborough University Institutional Repository. IDATER Archive: https://dspace.lboro.ac.uk/dspace-jspui/

Department of Education, Science and Training [DEST]. (2003). Australia's teachers: Australia's future. Advancing innovation, science, technology and mathematics. Background data and analysis. Canberra, ACT: Commonwealth of Australia.

Dow, W. (2006). The need to change pedagogies in science and technology subjects: European perspective. International Journal of Technology and Design Education, 16(3), 307-321.

Duschl, R. (2008). Science education in three-part harmony: Balancing conceptual, epistemic, and social learning goals. Review of Research in Education, 32(1), 268-291.

Education Queensland. (2003). The new basics project. Retrieved 1 September, 2008, from: http://education.qld.gov.au/corporate/newbasics/

Education Queensland. (2004). New basics research report. Retrieved 1 September, 2008, from: http://education.qld.gov.au/corporate/newbasics/html/research/research.html

Engineering Council. (1990). Policy statement: Standards and routes to registration (2nd ed.). London: Author.

Gardner, P., Penna, C., \& Brass, K. (1990). Technology and science: Meanings and educational implications. The Australian Science Teachers Journal, 36(3), 22-28.

Hannover, B, \& Kessels, U. (2004). Self-to-prototype matching as a strategy for making academic choices. Why high school students do not like math and science. Learning and Instruction, 14, 5167.

International Technology Education Association [ITEA]. (2007). Standards for technological literacy: Content for the study of Technology. Reston, VA: Author.

ITEA. (2008). technologically literate citizens. Retrieved 1 September, 2008, from: http://www.iteaconnect.org/TAA/TAA_Literacy.html.

King, D., \& Ritchie, S.M. (in press). Learning science through real-world contexts. In B. Fraser, K. Tobin, \& C. McRobbie (Eds.), Second international handbook of science education. Dordrecht, The Netherlands: Springer.

Lave, J., \& Wenger, E. (1990). Situated learning: Legitimate peripheral participation. Cambridge, UK: Cambridge University Press.

Lemke, J.L., (1990). Talking science: Language, learning and values. Norwood, NJ: Ablex.

Lewis, T. (2006). Design and inquiry: Bases for an accommodation between science and technology education and curriculum? Journal of Research in Science Teaching, 43(3), 255-281.

Lewis, T., Barlex, D., \& Chapman, C. (2007). Investigating the interaction between science and design \& technology (D\&T) in the secondary school - a case study approach. Research in Science and Technology Education, 25(1), 37-58.

McCormick, R. (1997). Conceptual and procedural knowledge. International Journal of Technology and Design Education, 7(1-2), 141-159.

McCormick, R. (2004). Issues of learning and knowledge in technology education. International Journal of Technology and Design Education, 14(1), 22-44. 


\section{NORTON \& RITCHIE}

McCormick, R., Davidson, M., \& Levinson, R. (1995). Making connections: Students using science understanding of electric circuits. In J.S. Smith (Ed.), IDATER 95 - International conference on design and technology educational research and curriculum development (pp. 63-67). Loughborough, UK: University of Loughborough.

McCormick, R., \& Evans, H. (1998, August). The use of mathematics in secondary school d\&t. A paper presented at the British Educational Research Association Annual Conference, Belfast, August 2730.

McNair, V., \& Clarke, R. (2007). Effective technology and design teaching: Getting it right in the classroom. International Journal of Technology and Design Education, 17(3), 271-290.

Mettas, A., \& Constantinou, C. (2007). The technology fair: A project-based learning approach for enhancing problem solving skills and interest in design and technology education. International Journal of Technology and Design Education, 18, (1), 79-100.

National Academy of Engineering. (2008a). Technically speaking. What is tech lit? Retrieved 28 August, 2008, from: http://www.nae.edu/nae/techlithome.nsf/weblinks/KGRG569LNP?OpenDocument.

National Academy of Engineering. (2008b). Technically speaking. What's been done?. Retrieved November 10, 2008, from: http://www.nae.edu/nae/techlithome.nsf/weblinks/KGRG-55X6N7?Open Document.

National Numeracy Review Panel \& National Numeracy Review Secretariat. (2007). National Numeracy Review: Background Paper, June 2007. Retrieved January 1, 2009, from: http://www.dest.gov.au/NR/rdonlyres/A6687654-F732-44CF-B39F-16511ADFBE2/18249/ NumeracyReviewBackgroundPaper.pdf

Norton, S.J. (2005). The constructional of proportional reasoning. In H. Chick \& J. Vincent (Eds.), Proceedings of the $29^{\text {th }}$ conference of the International Group for the Psychology of Mathematics Education (pp. 17-23). Department of Science and Mathematics Education University of Melbourne.

Norton S.J. (2006a). The use of design practice to teach mathematics and science. International Journal of Technology and Design Education, 18(1), 19-44.

Norton, S.J. (2006b). Pedagogies for the engagement of girls in the learning of proportional reasoning through technology practice. Mathematics Education Research Journal. 18(3), 69-99.

Norton, S.J., \& Cooper, T.J. (2008). Teaching mathematics and technology through design practice. In M. Goos, R. Brown, \& K. Makar (Eds.), Navigating currents and charting directions. Proceedings of the $31^{\text {th }}$ annual conference of the Mathematics Education Research Group of Australasia (pp. 377-384). Brisbane: The University of Queensland, St Lucia.

Norton, S.J., McRobbie, C.J., \& Ginns. I.S. (2007). Problem solving in a middle school robotics design classroom. Research in Science Education, 37(3), 261-277.

Paechter, C. (1995). Subcultural retreat: Negotiating the design and technology curriculum. British Educational Research Journal, 21(1), 75-87.

Queensland Studies Authority [QSA]. (2003). Technology: Years 1-10 syllabus. Brisbane, Qld: Author.

Ritchie, S.M. (1999). The craft of intervention: The construction of a teacher's personal practical theory for science learning and teaching during teacher-student interactions. Science Education, 83(2), 213231.

Ritchie, S.M., \& Hampson, B. (1996). Learning in-the-making: A case study of science and technology projects in a year six classroom. Research in Science Education, 26(4), 391-407.

Ritchie, S.M., Tobin, K., Roth, W.-M., \& Carambo, C. (2007). Transforming an academy through the enactment of collective curriculum leadership. Journal of Curriculum Studies, 39(2), 151-175.

Roth, W.-M. (1995). Authentic school science. Dordrecht, The Netherlands: Kluwer.

Roth, W.-M. (1998). Designing communities. Dordrecht, The Nethelands: Kluwer.

Roth, W.-M. (2005). Talking science: Language and learning in science classrooms. Oxford: Rowman \& Littlefield.

Roth, W.-M., Tobin, K., \& Ritchie, S. (2001). Re/Constructing elementary science. New York: Peter Lang. 
Wicklein, R., \& Schell, J. (1995). Case studies of multidisciplinary approaches to integrating mathematics, science and technology education. Journal of Technology Education, 6(2), 59-76.

Wilhelm, J., Sherrod, S., \& Walters, K. (2008). Project-based learning environments: Challenging preservice teachers to act in the moment. Journal of Educational Research, 101(4), 220-235.

Yurtseven, H. (2002). How does the image of engineering affect student recruitment and retention? A perspective from USA. Global Journal of Engineering Education, 6(1), 17-23.

\section{Stephen Norton}

Griffith University

School of Curriculum Teaching and Learning

Mount Gravatt Campus

Messines Ridge Road

Nathan 4111

Queensland

Stephen M. Ritchie

School of Mathematics, Science \& Technology Education

Queensland University of Technology

Brisbane

Australia 